\title{
Simplifying the calculation of light scattering properties for black carbon fractal aggregates
}

\author{
A. J. A. Smith and R. G. Grainger \\ Atmospheric, Oceanic and Planetary Physics, Clarendon Laboratory, Oxford, OX1 3PU, UK \\ Correspondence to: A. J. A. Smith (smith@atm.ox.ac.uk) \\ Received: 20 December 2013 - Published in Atmos. Chem. Phys. Discuss.: 7 February 2014 \\ Revised: 28 May 2014 - Accepted: 1 July 2014 - Published: 7 August 2014
}

\begin{abstract}
Black carbon fractal aggregates have complicated shapes that make the calculation of their optical properties particularly computationally expensive. Here, a method is presented to estimate fractal aggregate light scattering properties by optimising simplified models to full light scattering calculations. It is found that there are no possible spherical models (at any size or refractive index) that well represent the light scattering in the visible or near-thermal infrared. As such, parameterisations of the light scattering as a function of the number of aggregate particles is presented as the most pragmatic choice for modelling distributions of black carbon when the large computational overheads of rigorous scattering calculations cannot be justified. This parameterisation can be analytically integrated to provide light scattering properties for lognormal distributions of black carbon fractal aggregates and return extinction cross sections with $0.1 \%$ accuracy for typical black carbon size distributions. Scattering cross sections and the asymmetry parameter can be obtained to within $3 \%$.
\end{abstract}

\section{Introduction}

Particulate products of incomplete combustion, such as black carbon (BC), have been the subject of recent intense discussion (e.g. Jacobson, 2002, 2003; Bond, 2007; Bond et al., 2013). Emissions rates are high (Bond et al., 2004) and have tripled in the last $140 \mathrm{yr}$ (Ito and Penner, 2005), although specific regions have not followed this trend. The developed world has reduced emissions, while Asian countries have come to dominate carbon aerosol emission (Streets et al., 2003). Since BC has a high imaginary part of refractive index, it is one of the few aerosols that has a positive direct effect on radiative forcing (Jacobson, 2001; Bond, 2007; Bahadur et al., 2011).

Studies have shown that, when BC is deposited on snow, the lowering of surface albedo leads to faster run-off and to an additional warming effect (e.g. Flanner et al., 2009; Doherty et al., 2010), although other absorbing aerosols also play a role (Bond et al., 2013). Aside from the positive radiative forcing due to $\mathrm{BC}$, there are considerable negative health effects from fine particulate matter (Dockery et al., 1993; Jansen et al., 2005) and, in urban environments, issues of poor visibility (Larson et al., 1989).

Black carbon fractal aggregates (BCFAs) are clusters of $\mathrm{BC}$ spherules forming aerosols with a non-spherical shape. Accurate quantification of their optical properties is important both for their measurement and for predicting their radiative effect. Current estimates of the climate forcing caused by $\mathrm{BC}$ emissions are positive with a typical value of $1.1 \mathrm{~W} \mathrm{~m}^{-2}$ (Bond et al., 2013).

The object of this work is to see whether there are spheres (of some radius, $r$, and complex refractive index, $m$ ) whose optical properties are close enough to a BCFA's light scattering properties (as calculated using T-Matrix code) to acceptably represent these particles. If some mapping of $r$ and $m$ to properties of the BCFA can be found, there may be additional physical insight into the fractal light scattering, additional to the advantage of a much simpler scattering calculation.

After a brief description of black carbon, we show that this is not possible within the bounds of reasonably sized spheres with a wide range of refractive indices and go on to present a parameterisation of BCFA light scattering properties. 


\subsection{A physical description of aerosol formation and ageing}

Formation of submicron aggregate aerosols from burning is a rapid process involving several stages, some of which are irreversible. Initially, due to very high temperatures, some of the burning fuel vaporises (if it is not already gaseous). If the fuel is something such as coal, the main products could be inorganics and elemental carbon formed from the vaporised coal ash (Helble et al., 1988; Turns, 2000). In the case of biomass, this could be organics such as benzene and polyaromatic hydrocarbons (PAH) (Reid et al., 2005).

Further away from the hottest part of the flame, nucleation of these molecules leads to the formation of very small particles with diameters of $1-2 \mathrm{~nm}$ (Calcote, 1981). These quickly grow by coagulation and surface condensation to sizes of 10 $30 \mathrm{~nm}$. Coagulation is encouraged initially due to a high proportion of hydrocarbon radicals, which falls off as the particles age (Homann, 1967; Calcote, 1981). High-resolution transmission electron microscopy (TEM) images of individual carbonaceous spherules show them to be haphazardly ordered microstructures of graphene-like layers (Buseck et al., 1987; Pósfai et al., 1999; Li et al., 2003) with a very narrow range of diameters for a specific flame (Homann, 1967).

After the initial nucleation and coagulation, primary particles can aggregate, leading to the fractal $\mathrm{BC}$ aerosol often seen (e.g. Helble et al., 1988; Sorensen, 2001; Li et al., 2003; Zhang et al., 2008). As the particles pass through the edge of the flame, some will be oxidised, although not completely (Turns, 2000). Those that make it through the flame without burning are the $\mathrm{BC}$ emissions. Flames that burn more intensely have poorer transport of oxygen into the area where the particles are being created, and as a result will emit more particulate matter (Reid et al., 2005).

The aggregates created during burning last a very short amount of time, of the order of hours (Martins et al., 1998b), before being irreversibly deformed as the chain-like structures fold up into more spherical clusters (Martins et al., 1998a; Abel et al., 2003). Although the BC spherules are hydrophobic, their irregular shapes provide active sites where water can be deposited (Zhang et al., 2008). This change is thought to be due to atmospheric processing of the particles by nucleating water, and the coating of the carbon by nucleating additional products of the burning, e.g. sulphate and organic carbon (OC). This also means that the $\mathrm{BC}$ cores become coated in shells of other material which are generally hydrophilic (Popovicheva et al., 2008). This coating enhances the light absorption of the BC core (Fuller et al., 1999; Jacobson, 2001; Bond et al., 2006).

Once the BCFAs become hydrophilic, they can take on moisture and collapse into much more tightly packed "globules" (Mikhailov et al., 2006). These have greatly increased scattering and absorption cross sections and greater forward scattering (Yin and Liu, 2010; Liu et al., 2012). Some recent discussions have focused on apparent discrepancy in absorp- tion enhancement by the coating of BCFAs between measurement and models (Cappa et al., 2012, 2013; Jacobson, 2013). It has been noted that both the compactness and positioning of the BCFA within a coating medium have significant effects on mass absorption cross section (MAC) (Adachi et al., 2010; Scarnato et al., 2013).

\subsection{Fractal dimension}

Fractal aggregate particles are to some extent scale invariant, although they do not have the true scale invariance of a mathematical fractal, which would have infinite extent. They can be described in terms of the equation

$n_{\mathrm{s}}=k_{\mathrm{f}}\left(\frac{R_{\mathrm{g}}}{a}\right)^{D_{\mathrm{f}}}$,

where $n_{\mathrm{S}}$ is the number of spherules in the aggregate, $a$ is the radius of an individual spherule in the fractal, $D_{\mathrm{f}}$ is the fractal dimension, $k_{\mathrm{f}}$ is the fractal prefactor, and $R_{\mathrm{g}}$ is the radius of gyration which gives the root-mean-square (rms) distance of spherules from the cluster's centre of mass (Sorensen, 2001).

The fractal dimension gives a measure of the compactness of an aggregate. A $D_{\mathrm{f}}$ value of 1 describes an open-chain structure, whilst a $D_{\mathrm{f}}$ value of 3 describes a compact aggregate. This dependence of shape on $D_{\mathrm{f}}$ is shown in Fig. 1 .

For particles formed by diffusion-limited cluster aggregation (such as BC from flames), fractal dimensions of $D_{\mathrm{f}} \simeq$ $1.75 \rightarrow 1.8$ are expected (Sorensen, 2001).

\subsection{Light scattering methods}

The scattering of light by a spherical particle can be solved analytically using Mie's solution to Maxwell's equations (Mie, 1908; Bohren and Huffman, 1983). Additionally, the derivatives of all light scattering properties are also analytic (Grainger et al., 2004).

The scattering of light by fractal clusters can be calculated using the multiple-sphere T-Matrix Fortran-90 code (MSTM) (Mackowski, 2012), which is based on theory found in Mackowski and Mishchenko (1996). This method combines the spherical wave expansions for each spherule (at that spherules origin) in the aggregate, and orientationally averages. For this work, the results from this method are considered reference values.

An intermediate step between the rigour of MSTM and the simplicity of assuming spherical aerosols is RayleighDebye-Gans theory (RDG), which assumes that the individual scattering spherules are small enough to be Rayleigh scatterers, and that these scatterers have a negligible multiple scattering interaction with each other. Further details can be found in the review paper by Sorensen (2001). However, as noted by Bond and Bergstrom (2006, S5.2, and references therein), several studies have shown an underprediction of fractal aggregate absorption by RDG compared to 


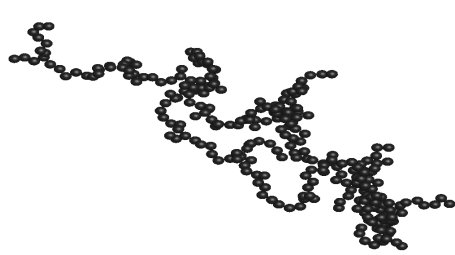

(a) $D_{f}=1.5$

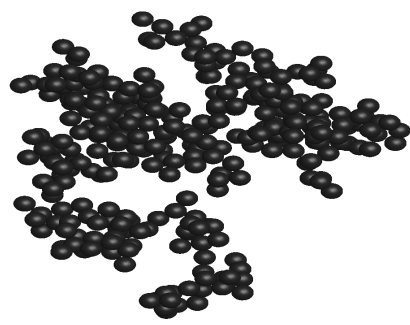

(c) $D_{f}=2.0$

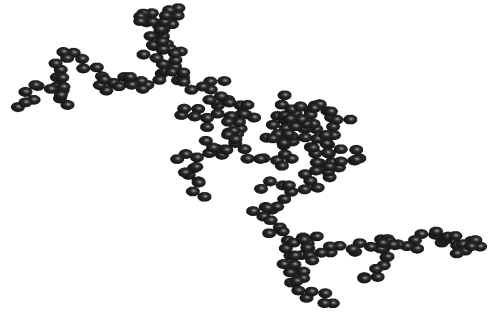

(b) $D_{f}=1.75$

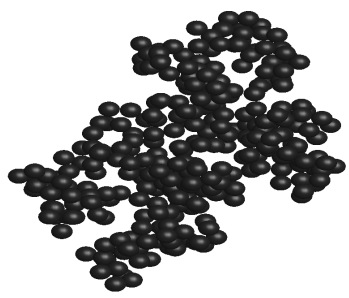

(d) $D_{f}=2.25$

Figure 1. Modelled fractal aggregates with $n_{s}=300, k_{\mathrm{f}}=1.25$, and varying values of $D_{\mathrm{f}}$. As the fractal dimension increases, we move from linear to bunched clusters. These aggregates were generated using a cluster-cluster algorithm.

rigorous light scattering calculations, particularly at longer wavelengths.

\section{Method}

Light scattering properties of BCFAs were calculated over a range of wavelengths, $\lambda$, from $400 \mathrm{~nm}$ to $15 \mu \mathrm{m}$ using the MSTM code. This required the input of individual spherule positions and radii within an aggregate, wavelength, and the refractive index. The fractal aggregates were generated using a cluster-cluster algorithm (Thouy and Jullien, 1994) with a spherule radius of $25 \mathrm{~nm}$ and fixed fractal prefactor of $k_{\mathrm{f}}=1.18$, which is very close to the value used by Liu and Mishchenko (2005), Zhao and Ma (2009), and Li et al. (2010). The spherule radius of $25 \mathrm{~nm}$ is representative of wood combustion aerosol (Gwaze et al., 2006) and has been noted to give the best agreement in single scatter albedo between measurements and calculations (Kahnert, 2010a). The burning of diesel fuels creates BCFAs with smaller spherules. More modern engines working in optimised combustion conditions can have spherules as small as $a=6.5 \mathrm{~nm}$, whilst emissions from black smoking diesel engines have sizes of $a=17.5 \mathrm{~nm}$ (Su et al., 2004). Future work will investigate the light scattering properties of these much smaller particles.

For $400 \mathrm{~nm} \leq \lambda \leq 1 \mu \mathrm{m}$, a step size of $\Delta \lambda=150 \mathrm{~nm}$ and a fixed refractive index of $m_{\mathrm{BC}}=1.95+0.79 i$ were selected, following Bond and Bergstrom (2006). Above this, the step size was widened to $\Delta \lambda=1 \mu \mathrm{m}$ and a parameterised refrac- tive index fit by Chang and Charalampopoulos (1990) was used. To alter the shape and size, the number of spherules was varied in steps of 20 with $20 \leq n_{\mathrm{s}} \leq 980$ and fractal dimension in steps of 0.1 with $1.6 \leq D_{\mathrm{f}} \leq 2.2$. Similar work by Kahnert (2012b) used fewer different sizes of BCFA, but attempted to find a "typical" geometry that was a good optical representation of BCFA at that size, by this method obtaining smoothly varying fields. In this study, only a single representation of each $n_{s}$ and $D_{f}$ particle was generated, and so one would expect occasional outliers in the output optical properties. Since the aim of this work was to find a mapping of complex shapes to simple spherical equivalents, it was thought that a parameterisation of the conversion would smooth out these issues. The calculated optical properties were the extinction and scattering cross sections, $\sigma_{\text {ext }}$ and $\sigma_{\text {sca }}$, and the asymmetry parameter, $g$, which gives a measure of the angular distribution of scattered light (Bohren and Huffman, 1983) and is used in several global circulation models (GCMs) to represent aerosol optical properties (e.g. Stier et al., 2007; Kahnert, 2012b).

Next, best fits of spherical radius and complex refractive index $(m=n+i k)$ of spheres were fitted to the individual BCFAs. Optimal estimation (Rodgers, 2000) and leastsquares fitting were tried. The differential optical properties required for the inversion, e.g. $\frac{\partial \sigma_{\mathrm{ext}}}{\partial r}$ and $\frac{\partial g}{\partial n}$, were obtained using Interactive Data Language (IDL) code described in Grainger et al. (2004).

When aggregates collapse into more tightly packed, higher- $D_{f}$ clusters, they are restructured by the changes in 

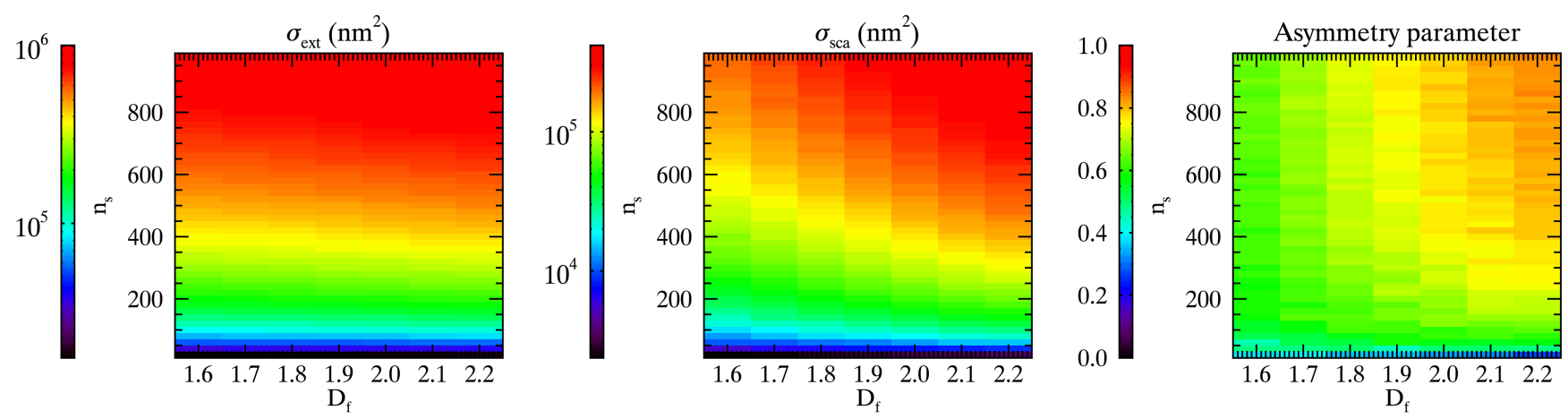

Figure 2. Extinction cross section, scattering cross section, and asymmetry parameter calculated using the MSTM code at $\lambda=550 \mathrm{~nm}$ for a range of fractal dimensions and numbers of spherules.

humidity and the coatings covering them. In these cases, the new shapes have formed in a fundamentally different manner from particles formed by the cluster-cluster algorithm used in this work (Thouy and Jullien, 1994) which gradually aggregates clusters to other clusters, never reordering previously added spherules within the aggregate. As such, the larger valued $D_{f}$ aggregates should not be taken as realistic models for compact BCFAs after atmospheric processing. This can be seen in comparisons of real compact BCFAs (e.g. Mikhailov et al., 2006; Zhang et al., 2008; Bambha et al., 2013) with Fig. 1d generated by the cluster-cluster algorithm.

\section{Results}

\subsection{Optical properties of black carbon fractal aggregates}

Figure 2 shows the extinction and scattering cross sections, and asymmetry parameter for BCFAs as a function of $D_{\mathrm{f}}$ and $n_{\mathrm{s}}$ in the visible. Although not clear from the figure (due to the logarithmic scale), the extinction cross section is broadly a function of the particle volume, suggesting that using the Rayleigh limit might be appropriate. The scattering cross section is more pronounced at higher $D_{\mathrm{f}}$ as the fractals become more densely packed and so a more coherent scattering entity, as also reported by Liu et al. (2008) and Scarnato et al. (2013). Similarly, $g$ shows a greater amount of the light being scattered forwards as the fractals become both more densely packed and larger.

Figure 3 shows the single scatter albedo $\left(\mathrm{SSA}=\sigma_{\text {sca }} / \sigma_{\text {ext }}\right)$, which agrees well with the literature review by Bond and Bergstrom (2006), who noted that, when measured, the SSA of BCFAs is "surprisingly consistent", with a value of $0.2-0.3$. MAC is another common parameter used to describe black carbon aerosols. Values of MAC at $\lambda=550 \mathrm{~nm}$ obtained by these calculations are shown in Fig. 4 and are consistent with similar calculations in the literature (Bond and Bergstrom, 2006; Kahnert, 2010a)

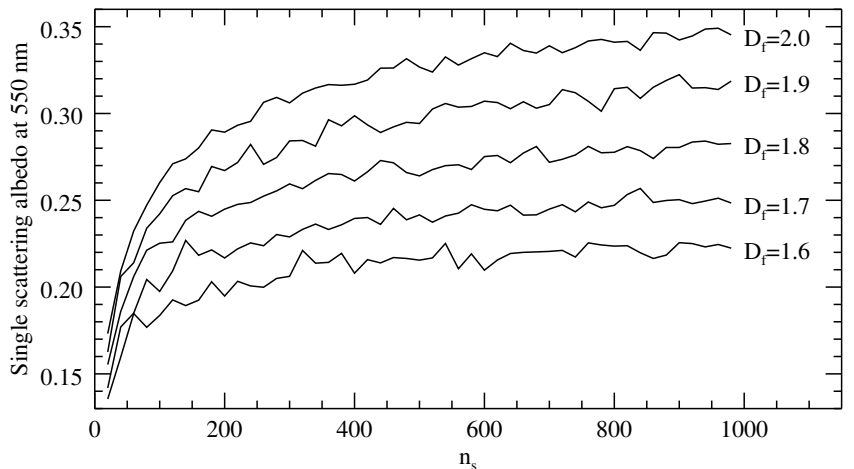

Figure 3. The SSA of BCFAs at $\lambda=550 \mathrm{~nm}$ as a function of $n_{\mathrm{S}}$ and $D_{\mathrm{f}}$. The most likely values of $D_{\mathrm{f}}$ would be from 1.7 to 1.8 , where the SSA values are between 0.2 and 0.3 .

which found calculated MAC values of around $6 \mathrm{~m}^{-2} \mathrm{~g}^{-1}$. There is a discrepancy between this and measured values of MAC, which are around $7.5 \mathrm{~m}^{-2} \mathrm{~g}^{-1}$. Results also agree with the work of Scarnato et al. (2013), who found that "lacy" aggregates had a higher MAC and lower SSA than more compact aggregates.

Since fractal aggregates are by nature randomly assembled, these are not the only possible representations of the light scattering properties that a BCFA with these properties could have. However, as shown in Fig. 5, relative difference from the mean values of the three parameters are small, with variance in the total extinction generally less than $1 \%$ away from the mean, and less than $5 \%$ away for $\sigma_{\text {sca }}$ and $g$ at $\lambda=550 \mathrm{~nm}$.

At $\lambda=12 \mu \mathrm{m}$, one might expect things to be more straightforward. The size parameter of the largest BCFAs studied are $x_{\mathrm{V}}=0.1$ and $x_{\mathrm{G}}=0.6$ (by equivalent volume and radius of gyration respectively), which would place the vast majority of studied equivalent spherical particles in the Rayleigh limit. In that case it would be expected that $g \simeq 0$ and that there would be little dependency of the cross sections with shape. Figure 6 shows BCFA light scattering at $12 \mu \mathrm{m}$, where 


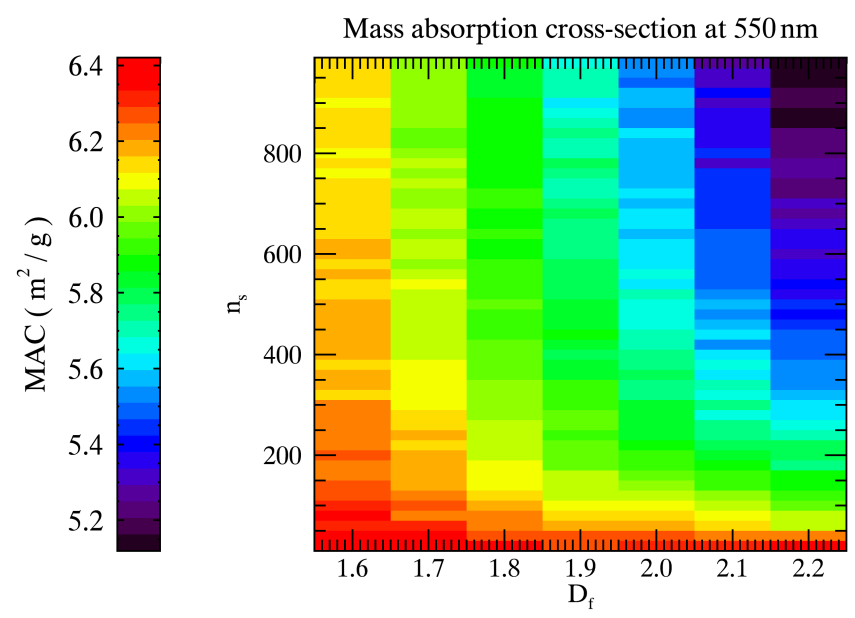

Figure 4. The mass absorption cross section at $\lambda=550 \mathrm{~nm}$ for $\mathrm{BC}$ FAs. This is the absorption cross section divided by the mass of the particles. For these calculations, a density of $1.8 \mathrm{~g} \mathrm{~m}^{-2}$ was assumed.

the refractive index is $m_{\mathrm{BC}}=2.93+2.16 i$. For particles with large $D_{\mathrm{f}}$ values, the asymmetry is close to zero, but this is not the case for larger particles with smaller fractal dimensions.

The calculations over the entire wavelength range are shown in Fig. 7 at a fixed fractal dimension of $D_{\mathrm{f}}=1.8$. Extinction cross sections decrease with decreasing size parameter (either because of increasing wavelength or decreasing numbers of spherules in the aggregate). Single scatter albedo and asymmetry also decrease with decreasing size parameter and increasing $k$.

\subsection{Finding appropriate spheres}

For all of the BCFAs, it was attempted to find matching optical properties using spheres with $50<r<1500 \mathrm{~nm}, 1<n<$ 4 , and $0<k<4$. Attempting to fit closest values of $\ln \sigma_{\text {ext }}$, $\ln \sigma_{\text {sca }}$, and $g$ using optimal estimation (Rodgers, 2000) is shown in Fig. 8 for $\lambda=550 \mathrm{~nm}$. We see relative errors of $>15 \%$ for extinction, $>20 \%$ for scattering, and $>40 \%$ for asymmetry at this wavelength, which are unacceptable and do not improve with increased wavelength. Additionally, sudden discontinuities in the fitted refractive index show that a regime change based on particle size would be required. Similar attempts fitting the single scatter albedo instead of $\ln \sigma_{\text {sca }}$, and $\sigma$ instead of $\ln \sigma$ values, also were not successful. Least-square fits were also unsuccessful.

One might expect that at longer wavelengths as the scattering BCFAs approached the Rayleigh limit the ability to fit spheres would improve. However, the asymmetry parameter at these wavelengths is non-negligible for the less compact and larger BCFAs (unlike Rayleigh scatterers) as can be seen in Figs. 6 and 7. This means that it is not possible to find spheres that can match $\ln \sigma_{\text {ext }}$ and $\ln \sigma_{\text {sca }}$, whilst also having a large enough $g$. As such, a trade-off between large errors in either the cross sections or asymmetry must be made. The fit with large errors in $g$ is shown in Fig. 9.

As such, it is suggested that within the range $0.4 \leq \lambda \leq$ $15 \mu \mathrm{m}$ there are no suitable sizes or refractive indices of spheres appropriate for the optical modelling of black carbon aggregates. Earlier work by $\mathrm{Li}$ et al. (2010) had found that it was not possible to represent the phase function for a reasonable size distribution of BCFAs with a similar distribution of spheres at wavelengths of $\lambda=0.628$ and $1.1 \mu \mathrm{m}$; so even had a good fit of $\sigma_{\text {ext }}, \sigma_{\text {sca }}$, and $g$ been found, it is unlikely that the full phase function resulting would have been appropriate.

\subsection{Parameterising fractal aggregate optical properties}

Since the extinction cross section scales with volume which is proportional to $n_{\mathrm{s}}$, a polynomial in $n_{\mathrm{s}}$ was chosen and order 3 was found to adequately capture the full range of $\lambda, D_{\mathrm{f}}$ and $n_{\mathrm{s}}$ used here.

$\sigma_{\mathrm{ext}}=\sum_{m=0}^{3} k_{\mathrm{m}} n_{\mathrm{s}}^{m}$

The scattering cross section is not so simple to parameterise, and so the SSA is fitted instead and multiplied by $\sigma_{\text {ext }}$ to obtain $\sigma_{\text {sca. }}$. The SSA and $g$ are both well captured by a logarithmic $n_{\mathrm{s}}$ and a linear offset. This was due to the tendency of these optical properties to initially increase with $n_{\mathrm{s}}$ before levelling off at large $n_{\mathrm{s}}$ :

$\mathrm{SSA}=w_{0}+w_{1} n_{\mathrm{s}}+w_{2} \ln n_{\mathrm{s}}$
$g=G_{0}+G_{1} n_{\mathrm{s}}+G_{2} \ln n_{\mathrm{s}}$

Table 1 shows the fit coefficients at $550 \mathrm{~nm}$ and $D_{\mathrm{f}}=1.8$. The root-mean-square errors (RMSEs) in $\sigma_{\text {ext }}$, SSA, and $g$ compared to the calculated values are also given. Including the smallest particles is roughly responsible for a doubling in the error of the fits, as can be shown by not including the two smallest particle sizes in the calculation. This is because the limit $\lim _{n_{\mathrm{s}} \rightarrow 0}\left(\sigma_{\text {ext }}\right)=0$ and $\lim _{n_{\mathrm{s}} \rightarrow 0}(g)=0$, leading to large inflation in the relative differences between points. Over the entire range of $\lambda$ and $D_{\mathrm{f}}$, errors in the visible are below $3 \%$ as shown in Fig. 10. In the range $2 \leq \lambda \leq 9 \mu \mathrm{m}$, RMSEs in SSA and $g$ can be as large as $10 \%$. Errors in extinction are $<10 \%$ in all cases.

In the work of Kahnert (2012b), attempts to parameterise the optical properties $\sigma_{\mathrm{abs}}$ with a cubic polynomial in the radius of equal volume, $r_{v}$, were successful, but fits of $\sigma_{\text {sca }}$, $g \times \sigma_{\text {sca }}$, and the backscatter cross section were unsuccessful. Instead, fits to the logarithm of these quantities were obtained which made analytic integration over $r_{v}$ to develop optical properties of size distributions of BCFA infeasible. As such, a look-up table of precomputed BCFA optical properties was used instead. In this work, that problem is not encountered since we are dealing with parameters of the properties we desire to integrate directly. 

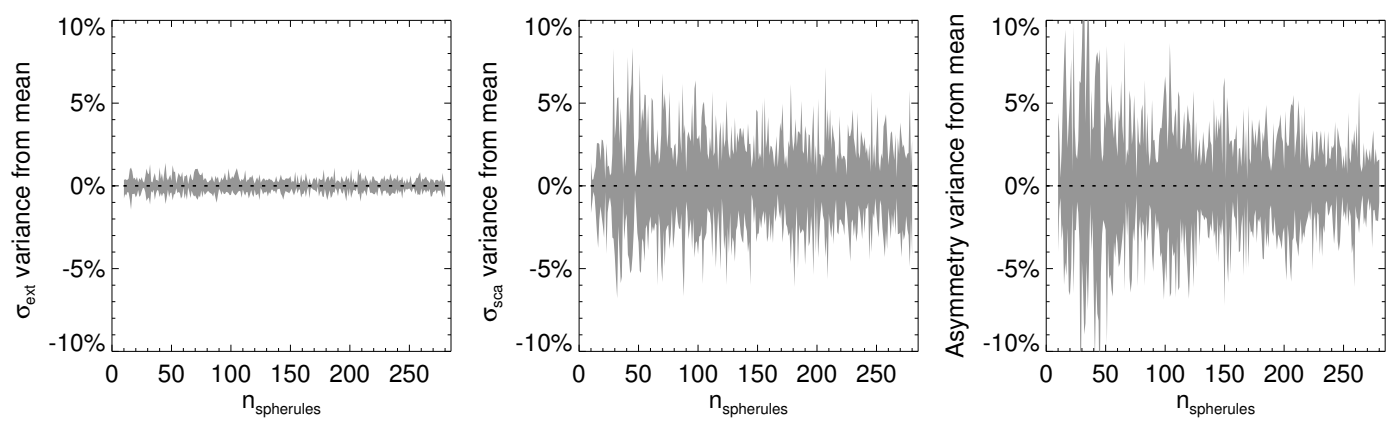

Figure 5. Showing the envelope of relative spread from the mean of the three output parameters $-\sigma_{\text {ext }}, \sigma_{\text {sca }}$ and $g-$ at $\lambda=550 \mathrm{~nm}$ for BC with $D_{\mathrm{f}}=1.75$, given four fractal geometries at each size. The high relative differences of $g$ with low $n_{\mathrm{S}}$ can be accounted for by the lower values of $g$ in this regime.
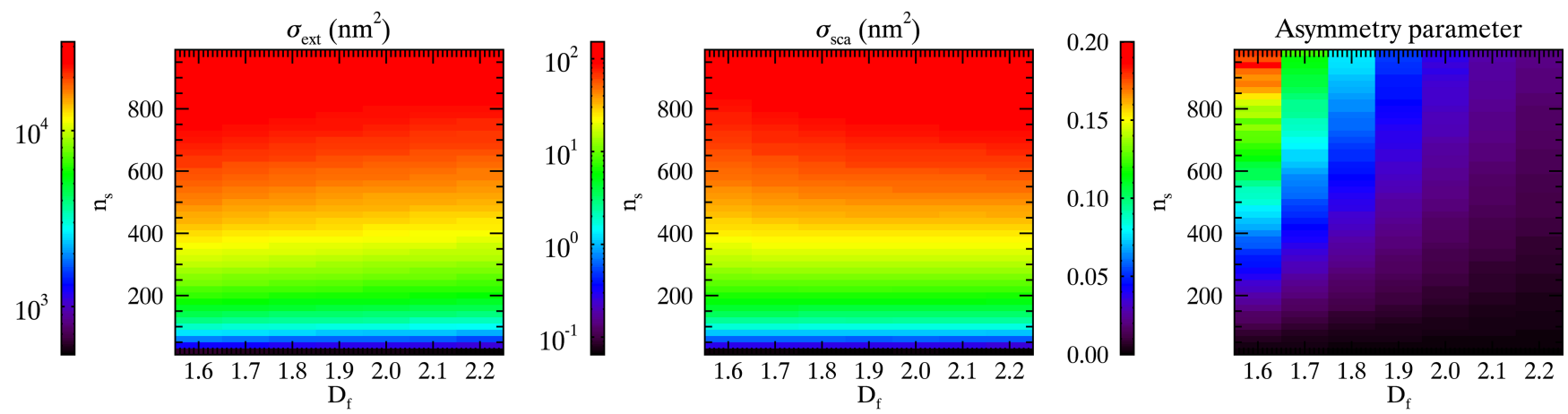

Figure 6. Extinction cross section, scattering cross section, and asymmetry parameter calculated using the MSTM code at $\lambda=12 \mu \mathrm{m}$ for a range of fractal dimensions and numbers of spherules.

Table 1. Fit coefficients for estimation of BCFA optical properties at $\lambda=550 \mathrm{~nm}$ and $D_{\mathrm{f}}=1.8$. Relative RMSEs for all fitted points, equally weighted, are also given. The lower values marked "Rel." ignore the first two data points where $n_{\mathrm{s}} \leq 40$, showing that this is where the majority of the relative error is contained. While the values of coefficient 1 (the linear term) in the fits of SSA and $g$ are negligible at $550 \mathrm{~nm}$, they increase at longer wavelengths, while the values of coefficient 2 (the logarithmic term) decrease.

\begin{tabular}{llll}
\hline Coeff. & $\sigma_{\text {ext }}$ & SSA & $g$ \\
\hline 0 & $-2.026 \times 10^{3}$ & $8.902 \times 10^{-2}$ & $2.669 \times 10^{-1}$ \\
1 & $9.581 \times 10^{2}$ & $0.000 \times 10^{0}$ & $0.000 \times 10^{0}$ \\
2 & $1.120 \times 10^{-3}$ & $2.876 \times 10^{-2}$ & $6.981 \times 10^{-2}$ \\
3 & $4.110 \times 10^{-6}$ & - & - \\
\hline RMSE & & & \\
Rel. & $0.50 \%$ & $2.53 \%$ & $5.02 \%$ \\
Rel. $^{*}$ & $0.25 \%$ & $1.64 \%$ & $2.13 \%$ \\
\hline
\end{tabular}

\subsection{Parameterising light scattering for a lognormal distribution of particles}

From these fitted optical schemes, the optical properties of lognormal distributions of these particles can be obtained trivially. For the extinction, we first relate $n_{\mathrm{S}}$ to a size distribution by volume-equivalent radius, $r$, saying

$r=a \sqrt[3]{n_{\mathrm{s}}}$,

and then insert it into a lognormal distribution defined as

$n(r)=\frac{N}{\sigma r \sqrt{2 \pi}} \exp \left[-\frac{1}{2}\left(\frac{\ln r-\ln r_{0}}{\sigma}\right)^{2}\right]$,

where $N$ is the total number of particles in the distribution, $\sigma$ is the standard deviation of $\ln r$, and $r_{0}$ is the geometric mean of $r$. The extinction coefficient at some point along the path of a light beam, $z$, is defined as

$\beta_{\text {ext }}(z)=\int_{0}^{\infty} \sigma_{\text {ext }}(r) n(r, z) \mathrm{d} r$.

Following from Eq. (2), $\sigma_{\text {ext }}$ can be separated into four terms in powers of $r^{3}$ :

$\sigma_{\mathrm{ext}}=\sum_{i=0}^{3} k_{\mathrm{m}}\left(\frac{r}{a}\right)^{3 \mathrm{~m}}$. 

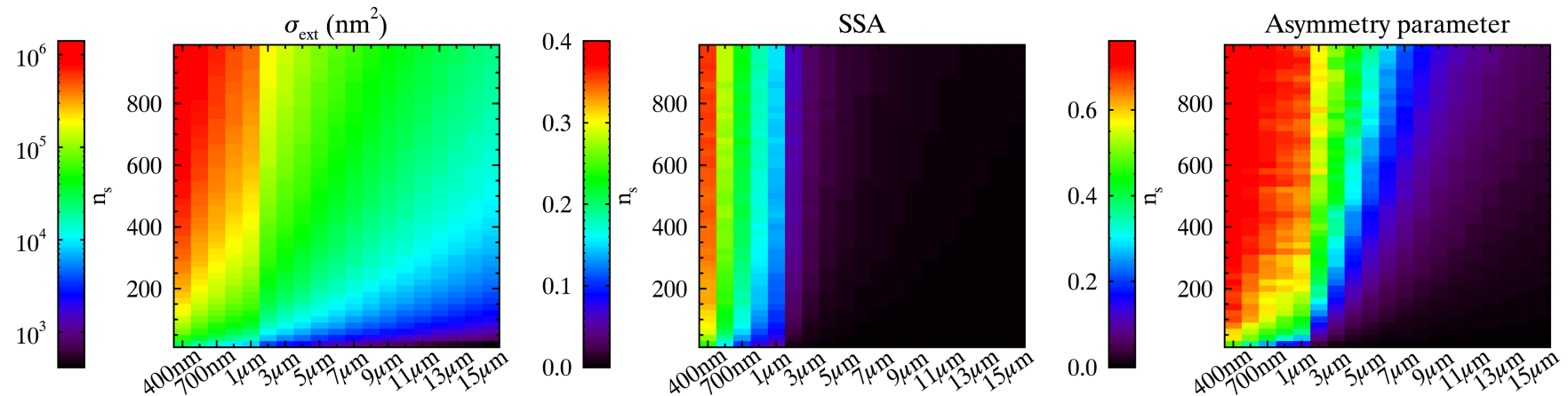

Figure 7. Extinction cross section, single scatter albedo, and asymmetry parameter calculated using the MSTM code at $D_{\mathrm{f}}=1.8$. Note the discontinuity in wavelength step size at $\lambda=1 \mu \mathrm{m}$. Unlabelled wavelengths are halfway between the two values on either side.
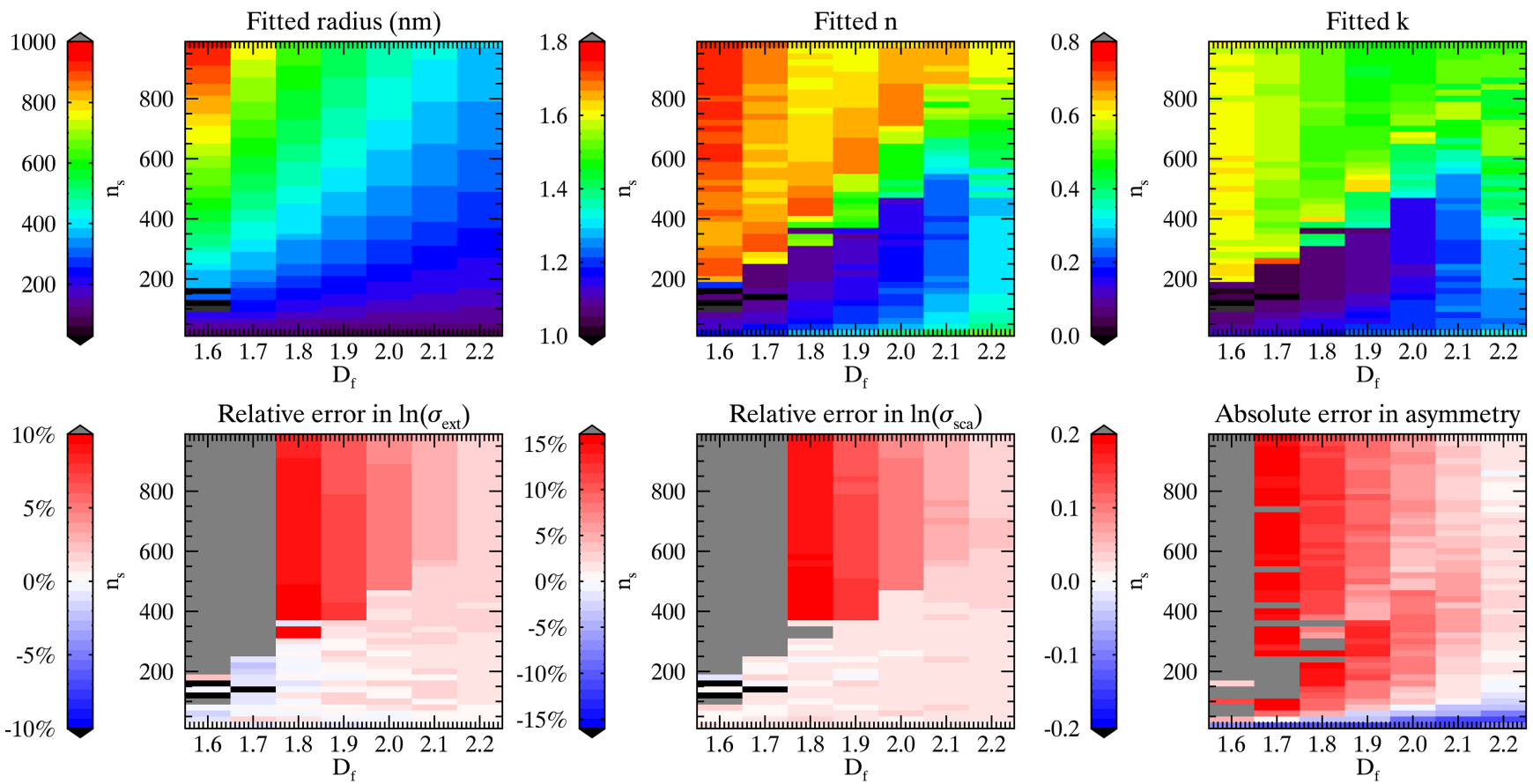

Figure 8. The optimum fitted sphere parameters $(r, n$, and $k)$ and their resultant errors relative to the reference MSTM calculations in $\ln \sigma_{\text {ext }}$ and $\ln \sigma_{\text {sca }}$, and absolute errors in $g$ for BCFAs with $\lambda=550 \mathrm{~nm}$. The colour scale has been adjusted so that the very large errors caused by unphysically small BCFA $D_{f}$ are clipped.

Finally, noting that

$\frac{1}{\sigma \sqrt{2 \pi}} \int_{0}^{\infty} r^{m-1} \exp \left[-\frac{1}{2}\left(\frac{\ln \frac{r}{r_{0}}}{\sigma}\right)^{2}\right] \mathrm{d} r=r_{0}^{m} e^{\frac{m^{2} \sigma^{2}}{2}}$,

an expression for $\beta_{\mathrm{ext}}$ is given by

$\beta_{\mathrm{ext}}=N \sum_{m=0}^{3} k_{\mathrm{m}}\left(\frac{r_{0}}{a}\right)^{3 \mathrm{~m}} e^{\frac{(3 \mathrm{~m} \sigma)^{2}}{2}}$.
Scattering is obtained from the extinction and single scatter albedo as

$$
\begin{aligned}
\beta_{\mathrm{sca}}(z) & =\int_{0}^{\infty} \sigma_{\mathrm{sca}}(r) n(r, z) \mathrm{d} r=\int_{0}^{\infty} \sigma_{\mathrm{ext}}(r) \operatorname{SSA}(r) n(r, z) \mathrm{d} r \\
& =\int_{0}^{\infty} \sum_{m=0}^{3} k_{\mathrm{m}}\left(\frac{r}{a}\right)^{3 \mathrm{~m}}\left[w_{0}+w_{1}\left(\frac{r}{a}\right)^{3}\right. \\
& \left.+w_{2} \ln \left(\frac{r}{a}\right)^{3}\right] n(r, z) \mathrm{d} r
\end{aligned}
$$



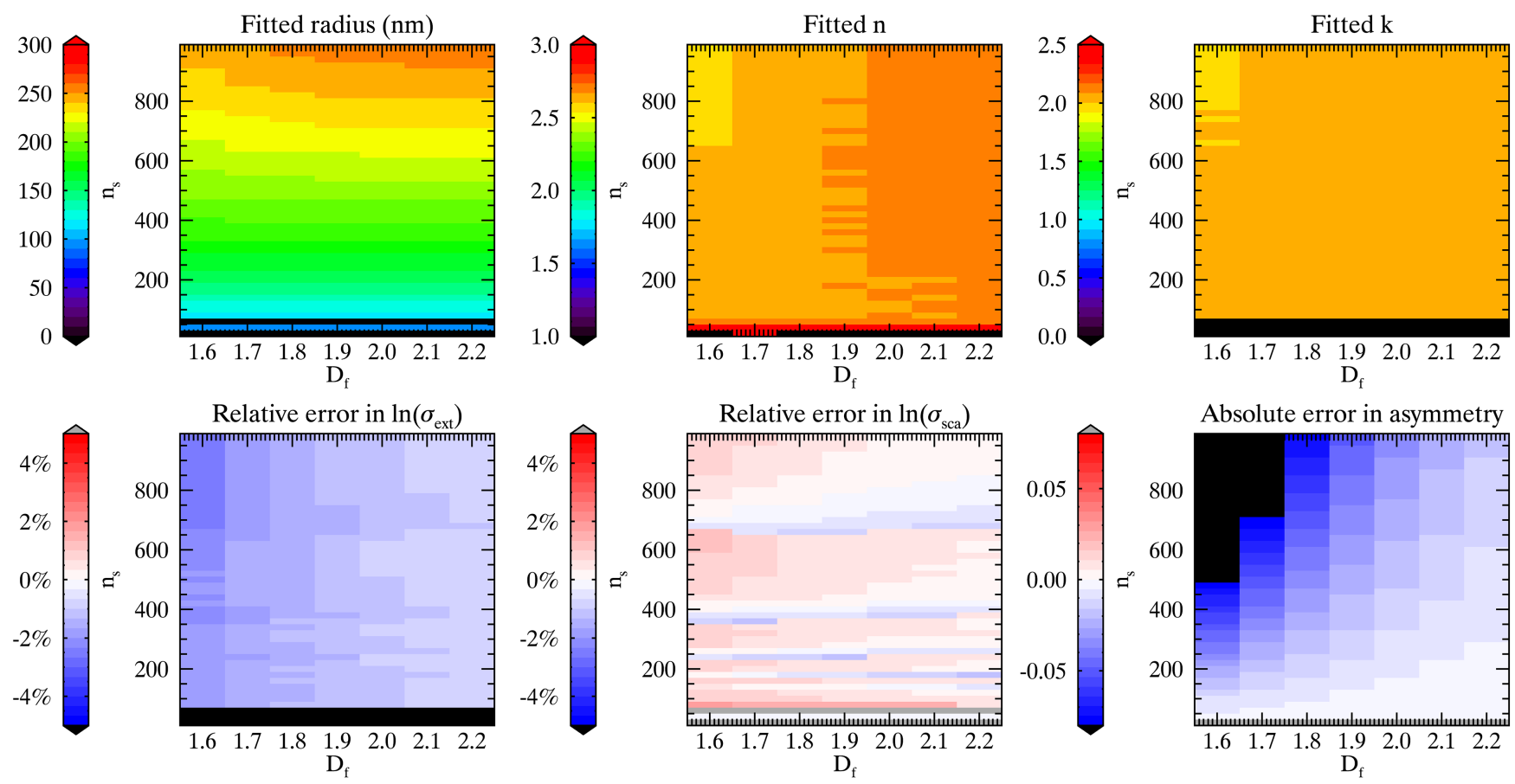

Figure 9. The optimum fitted sphere parameters $(r, n$, and $k)$ and their resultant relative errors in $\ln \sigma_{\text {ext }}$ and $\ln \sigma_{\text {sca }}$, and absolute errors in $g$ for $\lambda=12 \mu \mathrm{m}$. In this case, the errors on $g$ have been allowed to be large in order to get good fits in the cross sections. As a result, the fitted radius is close to the radius of equal volume (not shown), and the refractive indices are close to those used by the MSTM calculations $(m=2.93+2.16 i)$.

Using

$$
\begin{aligned}
& \frac{1}{\sigma \sqrt{2 \pi}} \int_{0}^{\infty} r^{m-1} \ln r \exp \left[-\frac{1}{2}\left(\frac{\ln \frac{r}{r_{0}}}{\sigma}\right)^{2}\right] \mathrm{d} r \\
& =r_{0}^{m} e^{\frac{m^{2} \sigma^{2}}{2}}\left(\ln r_{0}+m \sigma^{2}\right),
\end{aligned}
$$

this can be reduced to

$$
\begin{aligned}
& \beta_{\text {sca }}=N \beta_{\text {ext }}\left(w_{0}-3 w_{2} \ln a\right)+N \sum_{m=0}^{3} k_{\mathrm{m}}\left(\frac{r_{0}}{a}\right)^{3 \mathrm{~m}} e^{\frac{(3 m \sigma)^{2}}{2}} \\
& \times\left[w_{1}\left(\frac{r_{0}}{a}\right)^{3} e^{\frac{9 \sigma^{2}(2 m+1)}{2}}+3 w_{2}\left(\ln r_{0}+3 m \sigma\right)\right]
\end{aligned}
$$

Similar integration can be used to find the averaged asymmetry parameter for the size distribution, $<g>$, using

$<g>=\frac{\int_{0}^{\infty} \sigma_{\text {sca }}(r) g(r) n(r, z) \mathrm{d} r}{\beta_{\text {sca }}}$

by noting that

$$
\begin{aligned}
& \frac{1}{\sigma \sqrt{2 \pi}} \int_{0}^{\infty} r^{m-1} \ln ^{2} r \exp \left[-\frac{1}{2}\left(\frac{\ln \frac{r}{r_{0}}}{\sigma}\right)^{2}\right] \mathrm{d} r \\
& =r_{0}^{m} e^{\frac{m^{2} \sigma^{2}}{2}}\left[\left(\ln r_{0}+m \sigma^{2}\right)^{2}+\sigma^{2}\right] .
\end{aligned}
$$

Using a reasonable atmospheric $\mathrm{BC}$ size distribution $\left(r_{0}=\right.$ $120 \mathrm{~nm} ; \sigma=\ln 1.32$ ), differences between the extinction calculated by summing the various individual fractal calculations and the parameterisation were investigated. The method used is shown for the example of $\lambda=2 \mu \mathrm{m}$ and $D_{\mathrm{f}}=1.8$ in Fig. 11. The parameterisation is an integral over the whole of particle radius space, whereas the calculations of fractal optical properties were truncated at $n_{\mathrm{s}}=980(r=248 \mathrm{~nm})$. As such to check the validity of the integral parameterisation, the limit was set at $\int_{0}^{248 \mathrm{~nm}} f(r) \mathrm{d} r$. For all wavelengths and fractal dimensions, agreement between the two methods is within $3 \%$ for $g$ and $\sigma_{\text {sca }}$, and within $0.15 \%$ for $\sigma_{\text {ext }}$. Errors are slightly smaller than for individual scattering particles, since the parameterisation of individual particles roughly underestimates values as often as it overestimates.

The parameterisation is available as an Supplement to this work, and includes routines in IDL to implement extinction, scattering, SSA, and asymmetry parameter calculations for individual particles and lognormal distributions.

\section{Conclusions}

It has been shown that it is not possible to model the optical properties of black carbon fractal aggregates using spheres with refractive indices in the range $0 \leq m_{\mathrm{BC}} \leq 3+$ $3 i$ at any wavelength between $400 \mathrm{~nm}$ and $15 \mu \mathrm{m}$. Other 

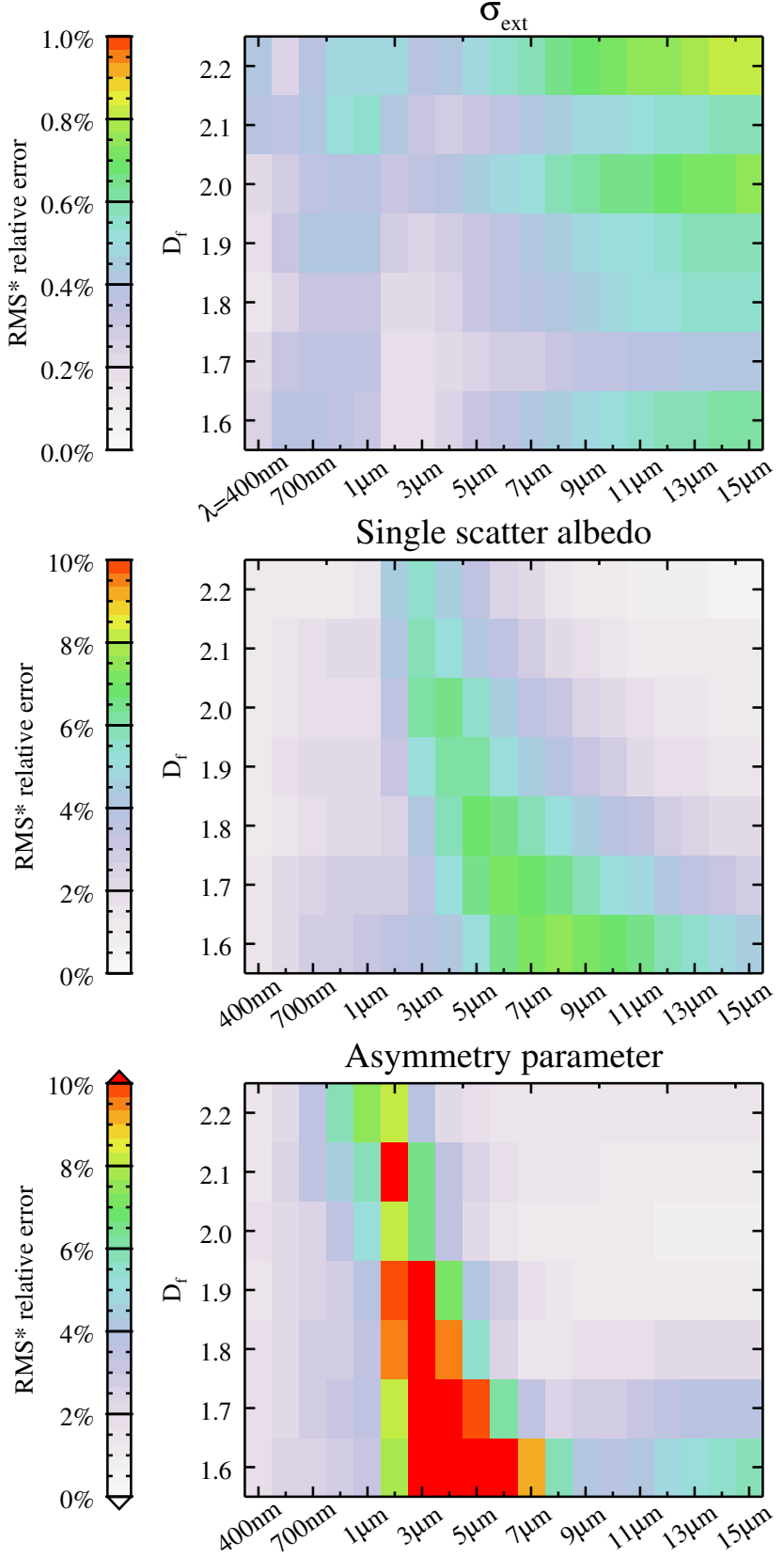

Figure 10. The relative RMSEs between the calculated and parameterised values of $\sigma_{\text {ext }}$, SSA, and $g$. Calculations of rms exclude the lowest two values of $n_{\mathrm{S}}$ as discussed in the text.

approximations, such as RDG, can improve greatly the representation of BCFA optical properties but generally do not provide sufficient absorption. With this in mind, a prudent step for GCMs requiring constantly changing distributions of $\mathrm{BC}$ aerosol could be to include a parameterisation, such as this one, which is computationally trivial to implement and is valid within the range of black carbon particles seen in the atmosphere. Uncertainties in the size distribution, shape, and composition of these particles should not be forgotten and
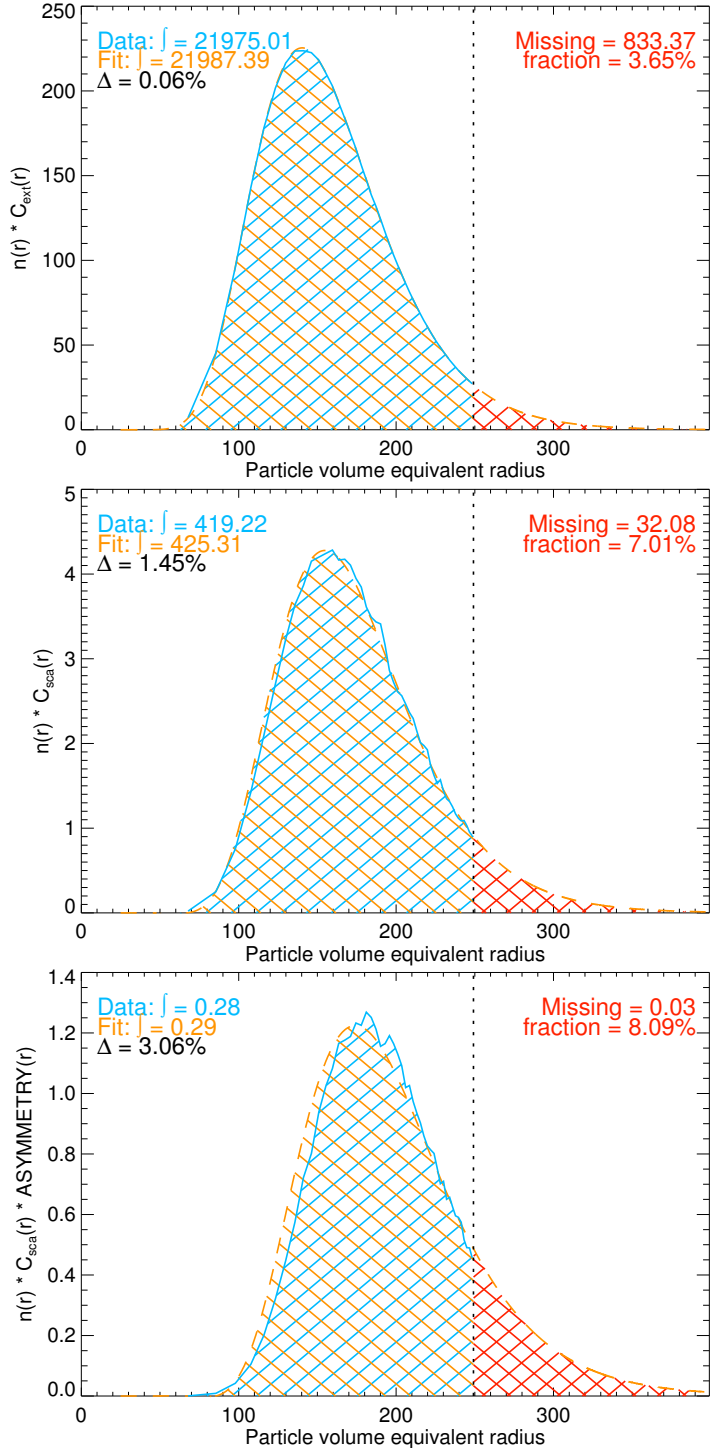

Figure 11. Comparing the integrals of extinction, scattering, and asymmetry from a sum of fractal optical properties, and the parameterisations described in the text. Differences between the parameterised fit and the data are compared only for the area bounded by the maximum value of $n_{\mathrm{s}}=980$. These calculations are for $D_{\mathrm{f}}=1.8$ and $\lambda=2 \mu \mathrm{m}$. The MSTM calculations (Data) are blue; the fitted data for the same radii (Fit) are orange; and the missing area covered by the fit, but not the MSTM calculations (Missing), are red. Numbers in these colours give the area under the respective curves. $\Delta$ gives the difference in areas between Data and Fit. The missing fraction is the fractional volume of Fit not covered by Data.

will certainly cause differences at least as large as the simplification of optical properties to spheres or RDG.

The Supplement related to this article is available online at doi:10.5194/acp-14-7825-2014-supplement. 
Acknowledgement. The authors acknowledge funding from the UK Natural Environment Research Council (NERC) National Centre for Earth Observation and the NERC project NE/F018142/1.

Edited by: N. Riemer

\section{References}

Abel, S. J., Haywood, J. M., Highwood, E. J., Li, J., and Buseck, P. R.: Evolution of biomass burning aerosol properties from an agricultural fire in southern Africa, Geophys. Res. Lett., 30, 1783, doi:10.1029/2003GL017342, 2003.

Adachi, K., Chung, S. H., and Buseck, P. R.: Shapes of soot aerosol particles and implications for their effects on climate, J. Geophys. Res., 115, D15206, doi:10.1029/2009JD012868, 2010.

Bahadur, R., Feng, Y., Russell, L. M., and Ramanathan, V.: Impact of California's air pollution laws on black carbon and their implications for direct radiative forcing, Atmos. Environ., 45, 11621167, doi:10.1016/j.atmosenv.2010.10.054, 2011.

Bambha, R. P., Dansson, M. A., Schrader, P. E., and Michelsen, H. A.: Effects of volatile coatings on the laserinduced incandescence of soot, Appl. Phys. B, 112, 343-358, doi:10.1007/s00340-013-5463-9, 2013.

Bohren, C. F. and Huffman, D. R.: Absorption and Scattering of Light by Small Particles, Wiley-VCH, doi:10.1002/9783527618156, 1983.

Bond, T. C.: Can warming particles enter global climate discussions?, Environ. Res. Lett., 2, 045030, doi:10.1088/17489326/2/4/045030, 2007.

Bond, T. C. and Bergstrom, R. W.: Light absorption by carbonaceous particles: an investigative review, Aerosol Sci. Tech., 40, 27-67, doi:10.1080/02786820500421521, 2006.

Bond, T. C., Streets, D. G., Yarber, K. F., Nelson, S. M., Woo, J.H., and Klimont, Z.: A technology-based global inventory of black and organic carbon emissions from combustion, J. Geophys. Res., 109, D14203, doi:10.1029/2003JD003697, 2004.

Bond, T. C., Habib, G., and Bergstrom, R. W.: Limitations in the enhancement of visible light absorption due to mixing state, J. Geophys. Res., 111, D20211, doi:10.1029/2006JD007315, 2006.

Bond, T. C., Doherty, S. J., Fahey, D. W., Forster, P. M., Berntsen, T., DeAngelo, B. J., Flanner, M. G., Ghan, S., Kärcher, B., Koch, D., Kinne, S., Kondo, Y., Quinn, P. K., Sarofim, M. C., Schultz, M. G., Schulz, M., Venkataraman, C., Zhang, H., Zhang, S., Bellouin, N., Guttikunda, S. K., Hopke, P. K., Jacobson, M. Z., Kaiser, J. W., Klimont, Z., Lohmann, U., Schwarz, J. P., Shindell, D., Storelvmo, T., Warren, S. G., and Zender, C. S.: Bounding the role of black carbon in the climate system: a scientific assessment, J. Geophys. Res., 118, 5380-5552, doi:10.1002/jgrd.50171, 2013.

Buseck, P. R., Huang, B., and Keller, L. P.: Electron microscope investigation of the structures of annealed carbons, Energ. Fuel., 1, 105-110, doi:10.1021/ef00001a020, 1987.

Calcote, H. F.: Mechanisms of soot nucleation in flames - a critical review, Combust. Flame, 42, 215-242, doi:10.1016/00102180(81)90159-0, 1981.

Cappa, C. D., Onasch, T. B., Massoli, P., Worsnop, D. R., Bates, T. S., Cross, E. S., Davidovits, P., Hakala, J., Hayden, K. L., Jobson, B. T., Kolesar, K. R., Lack, D. A., Lerner, B. M., Li, S.-M., Mellon, D., Nuaaman, I., Olfert, J. S.,
Petäjä, T., Quinn, P. K., Song, C., Subramanian, R., Williams, E. J., and Zaveri, R. A.: Radiative Absorption Enhancements Due to the Mixing State of Atmospheric Black Carbon, Science, 337, 1078-1081, doi:10.1126/science.1223447, 2012.

Cappa, C. D., Onasch, T. B., Massoli, P., Worsnop, D. R., Bates, T. S., Cross, E. S., Davidovits, P., Hakala, J., Hayden, K. L., Jobson, B. T., Kolesar, K. R., Lack, D. A., Lerner, B. M., Li, S.-M., Mellon, D., Nuaaman, I., Olfert, J. S., Petäjä, T., Quinn, P. K., Song, C., Subramanian, R., Williams, E. J., and Zaveri, R. A.: Response to Comment on "Radiative Absorption Enhancements Due to the Mixing State of Atmospheric Black Carbon", Science, 339, p. 393, doi:10.1126/science.1230260, 2013.

Chang, H. and Charalampopoulos, T. T.: Determination of the wavelength dependence of refractive indices of flame soot, P. Roy. Soc. Lond. A Mat., 430, 577-591, doi:10.1098/rspa.1990.0107, 1990.

Dockery, D. W., Pope, C. A., Xu, X., Spengler, J. D., Ware, J. H., Fay, M. E., Ferris, B. G., and Speizer, F. E.: An association between air pollution and mortality in six U. S. cities, New Engl. J. Med., 329, 1753-1759, doi:10.1056/NEJM199312093292401, 1993.

Doherty, S. J., Warren, S. G., Grenfell, T. C., Clarke, A. D., and Brandt, R. E.: Light-absorbing impurities in Arctic snow, Atmos. Chem. Phys., 10, 11647-11680, doi:10.5194/acp-1011647-2010, 2010.

Flanner, M. G., Zender, C. S., Hess, P. G., Mahowald, N. M., Painter, T. H., Ramanathan, V., and Rasch, P. J.: Springtime warming and reduced snow cover from carbonaceous particles, Atmos. Chem. Phys., 9, 2481-2497, doi:10.5194/acp-9-24812009, 2009.

Fuller, K. A., Malm, W. C., and Kreidenweis, S. M.: Effects of mixing on extinction by carbonaceous particles, J. Geophys. Res., 104, 15941-15954, doi:10.1029/1998JD100069, 1999.

Grainger, R. G., Lucas, J., Thomas, G. E., and Ewen, G. B.: Calculation of Mie derivatives, Appl. Optics, 43, 5386-5393, doi:10.1364/AO.43.005386, 2004.

Gwaze, P., Schmid, O., Annegarn, H. J., Andreae, M. O., Huth, J. and Helas, G.: Comparison of three methods of fractal analysis applied to soot aggregates from wood combustion, J. Aerosol Sci., 37, 820-838, doi:10.1016/j.jaerosci.2005.06.007, 2006.

Helble, J., Neville, M., and Sarofim, A. F.: Aggregate formation from vaporized ash during pulverized coal combustion, Symposium (International) on Combustion, 21, 411-417, doi:10.1016/S0082-0784(88)80268-6, 1988.

Homann, K. H.: Carbon formation in premixed flames, Combust. Flame, 11, 265-287, doi:10.1016/0010-2180(67)90017-X, 1967.

Ito, A. and Penner, J. E.: Historical emissions of carbonaceous aerosols from biomass and fossil fuel burning for the period 1870-2000, Global Biogeochem. Cy., 19, GB2028, doi:10.1029/2004GB002374, 2005.

Jacobson, M. Z.: Strong radiative heating due to the mixing state of black carbon in atmospheric aerosols, Nature, 409, 695-697, doi:10.1038/35055518, 2001.

Jacobson, M. Z.: Control of fossil-fuel particulate black carbon and organic matter, possibly the most effective method of slowing global warming, J. Geophys. Res., 107, 4410, doi:10.1029/2001JD001376, 2002. 
Jacobson, M. Z.: Reply to comment by J. E. Penner on "Control of fossil-fuel particulate black carbon and organic matter, possibly the most effective method of slowing global warming", J. Geophys. Res., 108, 4772, doi:10.1029/2003JD003403, 2003.

Jacobson, M. Z.: Comment on "Radiative Absorption Enhancements Due to the Mixing State of Atmospheric Black Carbon", Science, 339, p. 393, doi:10.1126/science.1229920, 2013.

Jansen, K. L., Larson, T. V., Koenig, J. Q., Mar, T. F., Fields, C., Stewart, J., and Lippmann, M.: Associations between health effects and particulate matter and black carbon in subjects with respiratory disease, Environ. Health Persp., 113, 1741-1746, doi:10.1289/ehp.8153, 2005.

Kahnert, M.: On the Discrepancy between Modeled and Measured Mass Absorption Cross Sections of Light Absorbing Carbon Aerosols, Aerosol Sci. Tech., 44, 453-460, doi:10.1080/02786821003733834, 2010a.

Kahnert, M.: Numerically exact computation of the optical properties of light absorbing carbon aggregates for wavelength of $200 \mathrm{~nm}-12.2 \mu \mathrm{m}$. Atmos. Chem. Phys., 10, 8319-8329, doi:10.5194/acp-10-8319-2010, 2010b.

Larson, S. M., Cass, G. R., and Gray, H. A.: Atmospheric carbon particles and the Los Angeles visibility problem, Aerosol Sci. Tech., 10, 118-130, doi:10.1080/02786828908959227, 1989.

Li, H., Liu, C., Bi, L., Yang, P., and Kattawar, G. W.: Numerical accuracy of "equivalent" spherical approximations for computing ensemble-averaged scattering properties of fractal soot aggregates, J. Quant. Spectrosc. Ra., 111, 2127-2132, doi:10.1016/j.jqsrt.2010.05.009, 2010.

Li, J., Pósfai, M., Hobbs, P. V., and Buseck, P. R.: Individual aerosol particles from biomass burning in southern Africa: 2. Compositions and aging of inorganic particles, J. Geophys. Res., 108, 8484, doi:10.1029/2002JD002310, 2003.

Liu, L. and Mishchenko, M. I.: Effects of aggregation on scattering and radiative properties of soot aerosols, J. Geophys. Res., 110, D11211, doi:10.1029/2004JD005649, 2005.

Liu, L., Mishchenko, M. I., and Arnott, W. P.: A study of radiative properties of fractal soot aggregates using the superposition T-matrix method, J. Quant. Spectrosc. Ra., 109, 2656-2663, doi:10.1016/j.jqsrt.2008.05.001, 2008.

Liu, C., Panetta, R. L., and Yang, P.: The Influence of Water Coating on the Optical Scattering Properties of Fractal Soot Aggregates, Aerosol Sci. Tech., 46, 31-43, doi:10.1080/02786826.2011.605401, 2012.

Mackowski, D. W.: MSTM - a multiple sphere T-matrix FORTRAN code for use on parallel computer clusters, Department of Mechanical Engineering, Auburn University, Auburn, AL 36849, USA, available at: http://eng.auburn.edu/users/ dmckwski/scatcodes (last access: June 2013), 2012.

Mackowski, D. W. and Mishchenko, M. I.: Calculation of the Tmatrix and the scattering matrix for ensembles of spheres, J. Opt. Soc. Am. A., 13, 2266-2278, doi:10.1364/JOSAA.13.002266, 1996.

Martins, J. V., Artaxo, P., Liousse, C., Reid, J. S., Hobbs, P. V., and Kaufman, Y. J.: Effects of black carbon content, particle size, and mixing on light absorption by aerosols from biomass burning in Brazil, J. Geophys. Res., 103, 32041-32050, doi:10.1029/98JD02593, 1998a.

Martins, J. V., Hobbs, P. V., Weiss, R. E., and Artaxo, P.: Sphericity and morphology of smoke particles from biomass burning in Brazil, J. Geophys. Res., 103, 32051-32057, doi:10.1029/98JD01153, 1998b.

Mie, G.: Beiträge zur Optik trüber Medien, speziell kolloidaler Metallösungen, Ann. Phys., 25, 377-445, a translation can be found at http://diogenes.iwt.uni-bremen.de/vt/ laser/papers/RAE-LT1873-1976-Mie-1908-translation.pdf (last access: 15 March 2011), 1908.

Mikhailov, E. F., Vlasenko, S. S., Podgorny, I. A., Ramanathan, V., and Corrigan, C. E.: Optical properties of soot-water drop agglomerates: An experimental study, J. Geophys. Res., 111, D07209, doi:10.1029/2005JD006389, 2006.

Popovicheva, O., Persiantseva, N. M., Shonija, N. K., DeMott, P., Koehler, K., Petters, M., Kreidenweis, S., Tishkova, V., Demirdjian, B., and Suzanne, J.: Water interaction with hydrophobic and hydrophilic soot particles, Phys. Chem. Chem. Phys., 10, 2332 2344, doi:10.1039/b718944n, 2008.

Pósfai, M., Anderson, J. R., Buseck, P. R., and Sievering, H.: Soot and sulfate aerosol particles in the remote marine troposphere, J. Geophys. Res., 104, 21685-21693, doi:10.1029/1999JD900208, 1999.

Reid, J. S., Koppmann, R., Eck, T. F., and Eleuterio, D. P.: A review of biomass burning emissions part II: intensive physical properties of biomass burning particles, Atmos. Chem. Phys., 5, 799 825, doi:10.5194/acp-5-799-2005, 2005.

Rodgers, C. D.: Inverse Methods for Atmospheric Sounding: Theory and Practice, vol. 2 of Atmospheric, Oceanic and Planetary Physics, World Scientific Publishing Co., 2000.

Scarnato, B. V., Vahidinia, S., Richard, D. T., and Kirchstetter, T. W.: Effects of internal mixing and aggregate morphology on optical properties of black carbon using a discrete dipole approximation model, Atmos. Chem. Phys., 13, 5089-5101, doi:10.5194/acp-13-5089-2013, 2013.

Sorensen, C. M.: Light scattering by fractal aggregates: a review, Aerosol Sci. Tech., 35, 648-687, doi:10.1080/02786820117868, 2001.

Stier, P., Seinfeld, J. H., Kinne, S., and Boucher, O.: Aerosol absorption and radiative forcing, Atmos. Chem. Phys., 7, 5237-5261, doi:10.5194/acp-7-5237-2007, 2007.

Streets, D. G., Bond, T. C., Carmichael, G. R., Fernandes, S. D., Fu, Q., He, D., Klimont, Z., Nelson, S. M., Tsai, N. Y., Wang, M. Q., Woo, J.-H., and Yarber, K. F.: An inventory of gaseous and primary aerosol emissions in Asia in the year 2000, J. Geophys. Res., 108, 8809, doi:10.1029/2002JD003093, 2003.

Su, D. S., Müller, J.-O., Jentoft, R. E., Rothe, D., Jacob, E. and Schlögl, R.: Fullerene-like soot from EuroIV diesel engine: consequences for catalytic automotive pollution control, Top. Catal., 30-31, 241-245, doi:10.1023/B:TOCA.0000029756.50941.02, 2004.

Thouy, R. and Jullien, R.: A cluster-cluster aggregation model with tunable fractal dimension, J. Phys. A-Math. Gen., 27, 2953, doi:10.1088/0305-4470/27/9/012, 1994.

Turns, S. R.: An Introduction to Combustion - Concepts and Applications, 2nd edn., McGraw-Hill, 2000.

Yin, J. Y. and Liu, L. H.: Influence of complex component and particle polydispersity on radiative properties of soot aggregate in atmosphere, J. Quant. Spectrosc. Ra., 111, 2115-2126, doi:10.1016/j.jqsrt.2010.05.016, 2010.

Zhang, R., Khalizov, A. F., Pagels, J., Zhang, D., Xue, H., and McMurry, P. H.: Variability in morphology, hygroscop- 
icity, and optical properties of soot aerosols during atmospheric processing, P. Natl Acad. Sci. USA, 105, 10291-10296, doi:10.1073/pnas.0804860105, 2008.
Zhao, Y. and Ma, L.: Applicable range of the Rayleigh-DebyeGans theory for calculating the scattering matrix of soot aggregates, Appl. Optics, 48, 591-597, doi:10.1364/AO.48.000591, 2009. 